\title{
Antioxidant activity of different extracts of lotus (Nelumbo nuficera Gaertn) rhizome by gradient solvent extraction
}

\author{
Guoping REN ${ }^{1}$, Dongmei YANG ${ }^{1 *}$ (D)
}

\begin{abstract}
In vitro antioxidant activity of extracts of lotus rhizome with different solvent by gradient extraction was determined. The extraction yield and total phenolic content of extracts were determined. 1,1-diphenyl-2-picrylhydrazyl hydrate (DPPH) radical scavenging assay and $\beta$-carotene-linoleic acid assay were conducted to assess the antioxidant activity of the extracts. Results showed that the yield of butanol extract was the highest. The order of total phenolic content in different extracts was as follows: water extract $<$ petroleum ether extract $<$ chloroform extract $<$ butanol extract $<$ ethyl acetate extract, the same with that of the DPPH scavenging activity. The total phenolic content was significantly correlated with DPPH scavenging activity $\left(\mathrm{R}^{2}=0.9363\right)$. All extracts, except water extract with too poor antioxidant activity, showed obvious antioxidant activity against $\beta$-carotene-linoleic acid, and the antioxidant activity of butanol extract was significantly lower than others. There was no significant correlation between the antioxidant activity against $\beta$-carotene-linoleic acid and the total phenolic content $\left(\mathrm{R}^{2}=0.1995\right)$.
\end{abstract}

Keywords: lotus rhizome; extracts; antioxidant activity; solvent.

Practical Application: This study has provided a basis for further exploring the antioxidant value of lotus rhizome.

\section{Introduction}

Lotus (Nelumbo nucifera Gaertn) is both an ornamental plant and a dietary staple in Eastern Asia, particularly in China (Hu \& Skibsted, 2002). All parts of lotus are used for various medicinal purposes in oriental medicine (Kashiwada et al., 2005). The seed of lotus is used in folk remedies as diuretic, cooling agent, antiemetic and antidote in the treatment of tissue inflammation, cancer, skin disease, leprosy and poisoning (Chopra et al., 1956; Liu et al., 2004). The leaf of lotus is considered best for "over-coming body heat", and stopping bleeding (Bensky et al., 2004). It is used as a drug for hematemesis, epistaxis, hemoptysis, hematuria and metrorrhagia (Ono et al., 2006) in traditional Chinese medicine. Lotus rhizome can be cooked into different dishes or eaten raw as a common vegetable. Especially, it has been applied in Chinese herbal prescriptions to alleviate tissue inflammation, cancer, and liver cirrhosis for a long time (Mukherjee et al., 1997).

The extracts of lotus possess a wide variety of activities. The extracts of lotus talk shows anti-pyretic effect (Sinha et al., 2000), while extracts of lotus leaf and stamen show antioxidant effect and strong radical scavenging activity (Wu et al., 2003; Cho et al., 2003). It is reported that the extract of lotus rhizome exhibits high antioxidative capacity (Hu \& Skibsted, 2002). However, few researchers study the antioxidant activities of the extract of lotus rhizome with different solvent by gradient extraction. In the current study, active substance of lotus rhizome was extracted with increased polarity organic solvent by gradient extraction. The extraction yield and total phenolics content of different extract were determined. 1,1-diphenyl-2-picrylhydrazyl hydrate (DPPH) radical scavenging assay and $\beta$-carotene-linoleic acid assay were conducted to assess the antioxidant activity of the extract.

\section{Materials and methods}

\subsection{Materials and reagents}

Lotus rhizome (Dong he zao ou, named in China) was purchased from Yiwu (Zhejiang, China) and washed by water. DPPH, $\beta$-carotene, Folin-Ciocalteu (FC) reagent, gallic acid, linoleic acid and polyoxyethylene sorbitan monopalmitate (Tween 40) were obtained from SigmaAldrich (Saint Louis, USA). All other chemicals used were of analytical grade.

\subsection{Extraction method}

One kg of randomly mixed lotus rhizome of different sizes and parts was homogenated, then extracted with $60 \%$ ethanol aqueous solution. After filtered, ethanol was evaporated at $35^{\circ} \mathrm{C}$, then the water solution of extract was extracted with petroleum ether, chloroform, ethyl acetate and butanol in sequence. The solvent of each extract liquid was evaporated at $35^{\circ} \mathrm{C}$ and the remaining water solution was freeze-dried. The dried extracts were then weighed. The extraction process was showed in Figure 1.

\subsection{Determination of total phenolics content}

Determination of total phenolics content was carried out using Folin-Ciocalteu (FC) method with gallic acid as standard according to Slinkard \& Singleton (1997) with some modifications. $1.0 \mathrm{~mL}$ of FC reagent and proper amount of sample solution were added in a flask. The flask was shaken up to mix the solutions thoroughly. After $3 \mathrm{~min}, 3.0 \mathrm{~mL}$ of 


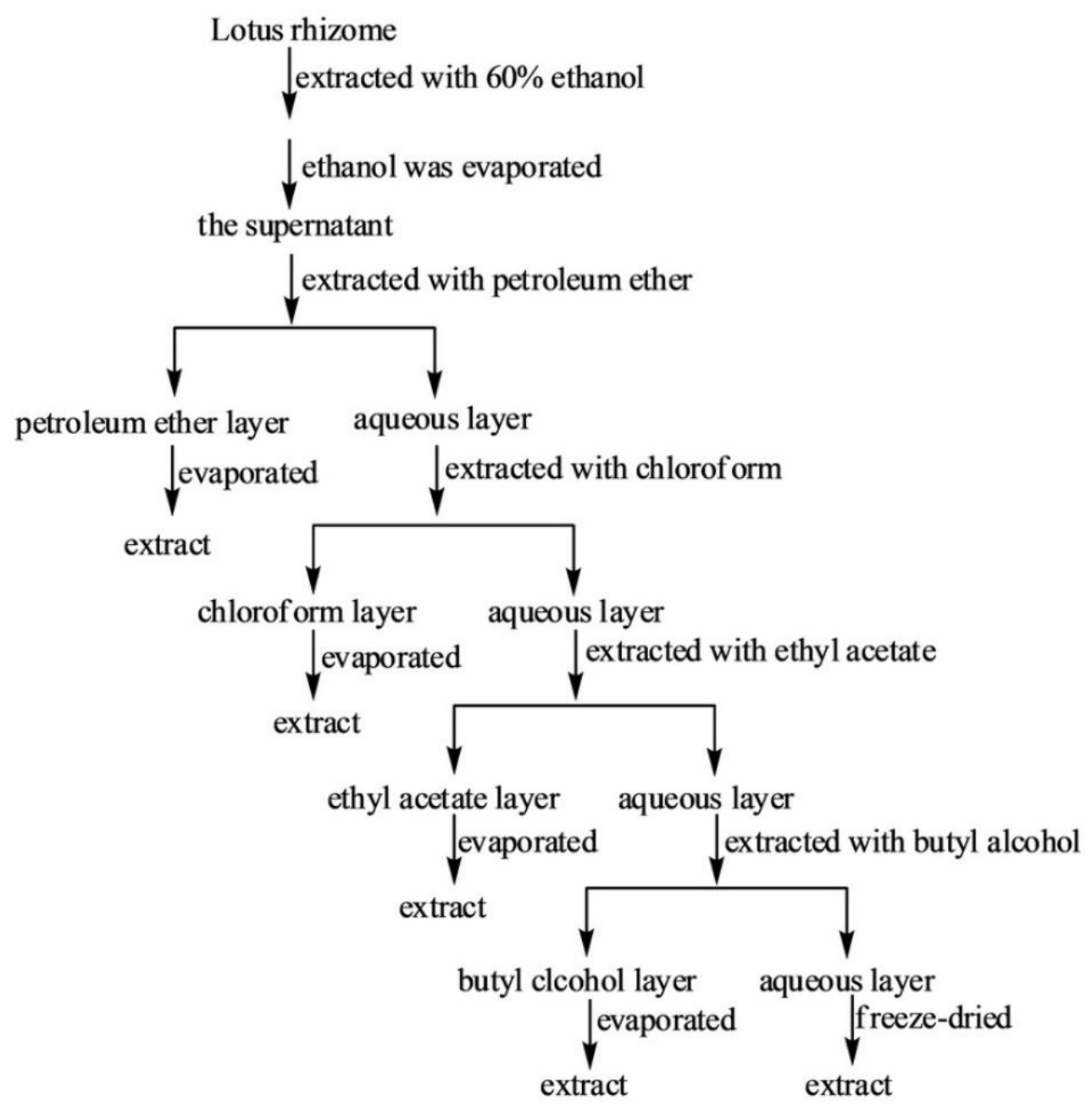

Figure 1. Extraction process of antioxidant constituents from lotus rhizome.

$\mathrm{Na}_{2} \mathrm{CO}_{3}$ solution (2\%) was added. The solutions were mixed again and left at room temperature for $2 \mathrm{~h}$. The absorbance was measured at $765 \mathrm{~nm}$ using a UV-Vis spectrophotometer. Total phenolics content of the extracts was calculated with a linear regression equation obtained from gallic acid standard graph: Absorbance $=8.3886 \times$ gallic acid $(\mu \mathrm{g})-0.0114$. Results were expressed as milligrams of gallic acid equivalents (GAE) per $100 \mathrm{~g}$ of extracts.

\subsection{Determination of DPPH radical scavenging capacity}

The scavenging activity on DPPH radicals was measured according to the method of Sánchez-Moreno et al. (1998) with some modifications. $0.2 \mathrm{~mL}$ of methanol solution of extracts was added to $2.8 \mathrm{~mL}$ of methanol solution of DPPH. The solutions were mixed thoroughly. After $3 \mathrm{~min}$, absorbance of the solutions was measured at $517 \mathrm{~nm}$ using a UV-Vis spectrophotometer. Methanol was used as a control. The DPPH radical scavenging activity of each sample was calculated by the DPPH inhibition (absorbance decrease) according to the following equation: $\mathrm{DPPH}$ inhibiton $(\%)=100^{*}\left(\mathrm{~A}_{\text {control }}-\mathrm{A}_{\text {sample }}\right) / \mathrm{A}_{\text {control }}$ (with $\mathrm{A}$ : absorbance).

\subsection{Determination of antioxidant activity by $\beta$-carotene bleaching method}

In $\beta$-carotene-linoleic acid assay, antioxidant capacity is determined by measuring the inhibition of the volatile organic compounds and the conjugated diene hydroperoxides arising from linoleic acid oxidation (Kartal et al., 2007). Total antioxidant activity of lotus rhizome extracts was measured according to the method of Moure et al. (2000). $2.0 \mathrm{mg}$ of $\beta$-carotene were dissolved in $10 \mathrm{~mL}$ chloroform and $1.0 \mathrm{~mL}$ of the $\beta$-carotene solution was mixed with $20 \mathrm{mg}$ of purified linoleic acid and $200 \mathrm{mg}$ of Tween 40 emulsifier in a round-bottom flask, chloroform was then removed in a rotary vacuum evaporator. After evaporation, the mixture was immediately diluted with $50 \mathrm{~mL}$ of distilled water and the mixture was stirred in a sonicator. $100 \mu \mathrm{L}$ of methanol solution of extracts was added to $9.9 \mathrm{~mL}$ of the $\beta$ - carotene/linoleic acid emulsion. Methanol was used as a control. Absorbance at $470 \mathrm{~nm}$ was immediately recorded after addition of sample. The vials were then gently capped and placed at $50^{\circ} \mathrm{C}$ in a water bath. The absorbance was determined every $20 \mathrm{~min}$ until $120 \mathrm{~min}$. Antioxidant activity coefficient (AAC) was measured in terms of successful bleaching of $\beta$-carotene by using a slightly modified version of the formula: $\mathrm{AAC}=1000^{*}\left(\mathrm{~A}_{\mathrm{S}(120)}-\mathrm{A}_{\mathrm{C}(120)}\right) /\left(\mathrm{A}_{\mathrm{C}(0)}-\mathrm{A}_{\mathrm{C}(120)}\right)$, where $A_{\mathrm{C}(0)}$ is the absorbance values measured at initial time of 
the incubation for control at $0 \mathrm{~min}$, while $A_{\mathrm{S}(120)}$ and $A_{\mathrm{C}(120)}$ are the absorbance values measured in the samples or control at $120 \mathrm{~min}$, respectively.

\subsection{Statistical analysis}

All analyses were run in triplicates and results averaged. Statistical analyses were performed with the Excel and SPSS software package.

\section{Results and discussion}

\subsection{Yield of lotus rhizome extracts}

As shown in Figure 2, the yields of lotus rhizome extract from wet weight by gradient extraction with different solvents were varied from 0.027 to $0.229 \mathrm{~g}$ extracts $/ 100 \mathrm{~g}$ lotus rhizome, ranging from low to high in the following order: ethyl acetate extract $<$ chloroform extract $<$ petroleum ether extract $<$ water extract $<$ butanol extract. The yield of butanol extracts was 8.48 times of that of ethyl acetate extract. This indicated that substances in lotus rhizome were quite polar and lots of polar compounds were mainly dissolved in water and alcohol.

\subsection{Total phenolic content of lotus rhizome extracts}

The total phenolic content of the extract, affected by the extracting solvents, was showed in Figure 3. The total phenolic content (mg GAE/100g extract) ranked from low to high in the following order: water extract $(0.7)<$ petroleum ether extract $(1.5)<$ chloroform extract $(2.1)<$ butanol extract $(4.1)<$ ethyl acetate extract (5.7), and there was a significant difference between any two of five extracts. This was in concordance with the research results of Wangensteen et al. (2004).

\subsection{DPPH radical scavenging activity of lotus rhizome extracts}

It is well accepted that the DPPH radical scavenging by antioxidant is attributable to their hydrogen donating activity (Krings \& Berger, 2001). This test system can be used for

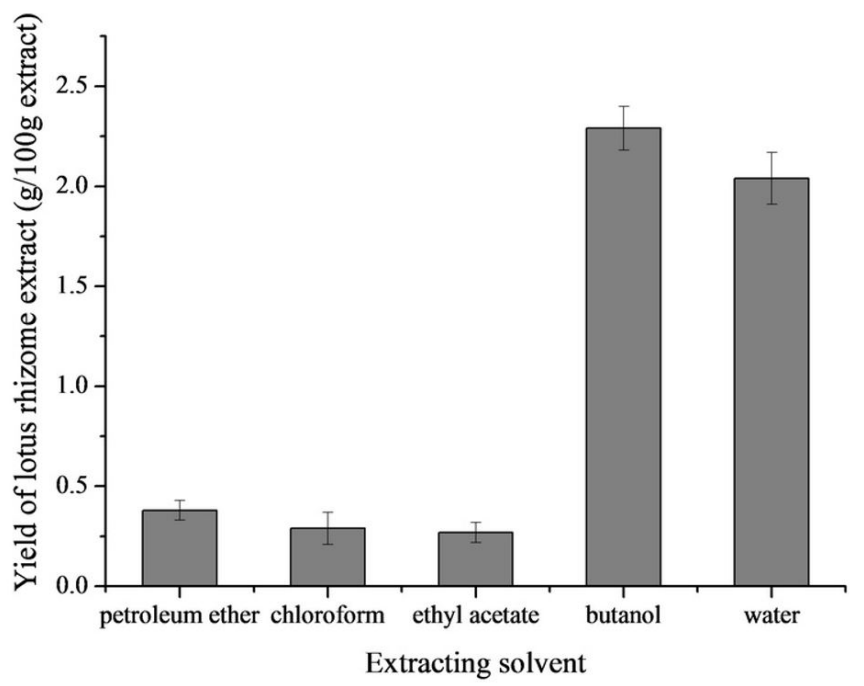

Figure 2. Yield of lotus rhizome extracts. the primary characterization of the scavenging potential of compounds, and is thus used in the present work for evaluation of the effectiveness of extracts of lotus rhizome. In experiment, the proper concentration of extract of petroleum ether, chloroform, ethyl acetate, butanol, and BHA was 41-400, 20-300, 11-55, 15.4366.86 , and $12.5-100 \mu \mathrm{g} / 3 \mathrm{~mL}$, respectively. The $\mathrm{DPPH}$ radical scavenging activity of water extract was too poor to consider in this study. Results were shown in Figure 4 and 5. The DPPH inhibition rate of all extracts and BHA increased when their concentrations increased. The order of DPPH inhibition rate of different extracts and BHA was as follows: petroleum ether extract $<$ chloroform extract $<$ butanol extract $<$ BHA $<$ ethyl acetate extract. IC50, the half maximal inhibitory concentration, represents the concentration of an inhibitor that is required for $50 \%$ inhibition. The IC50 value of ethyl acetate extract, BHA extract, butanol extract, chloroform extract and petroleum

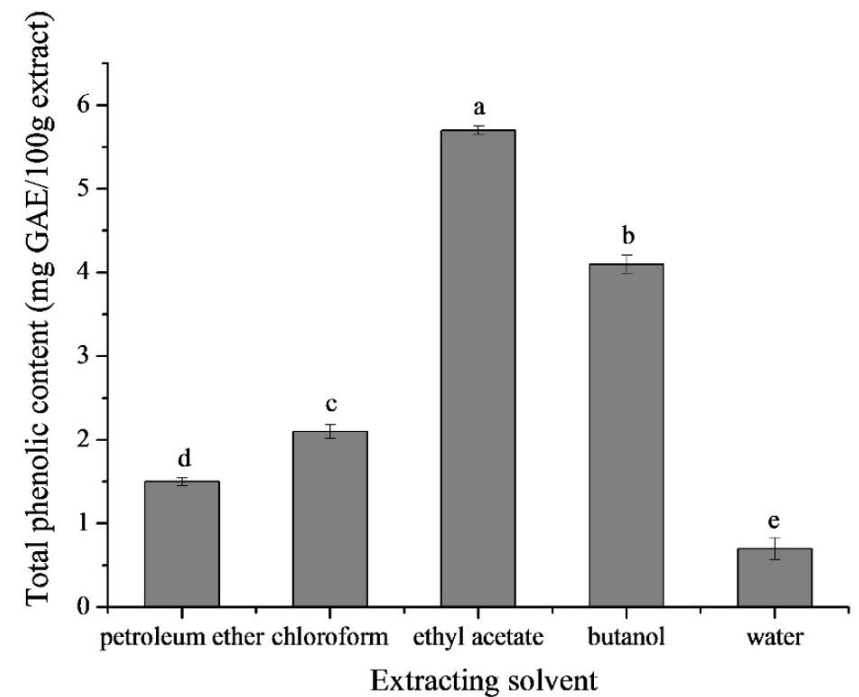

Figure 3. Total phenolic content of lotus rhizome extracts. Values in a column with different letters were significantly different $(P<0.05)$.

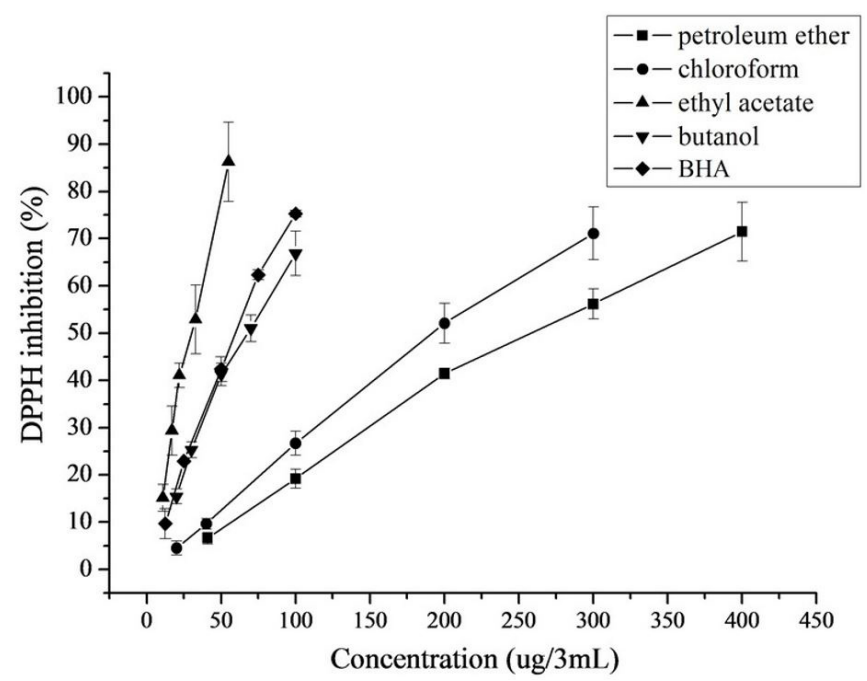

Figure 4. DPPH radical scavenging activity of lotus rhizome extracts. 
extract were $0.41,0.83,0.93,2.71$, and $3.59 \mathrm{mg} / \mathrm{mL}$, respectively. It was also found that the DPPH radical scavenging activity of different extracts was significantly correlated with the total phenolic content $\left(\mathrm{R}^{2}=0.9363\right)$. This indicated that the DPPH radical scavenging activity mainly attributed to the phenols in lotus rhizome.

\subsection{Antioxidant activity determined by $\beta$-carotene bleaching method}

The antioxidant activity of different extracts of lotus rhizome determined by $\beta$-carotene bleaching method was shown in Figure 6. All extracts, except water extract with too poor antioxidant activity, showed antioxidant activity against $\beta$-carotene-linoleic acid. The AAC values of the extracts were ranked in the order: butanol extract < ethyl acetate extract < chloroform extract $<$ petroleum ether extract. The antioxidant activity of butanol extract was significantly lower than others.

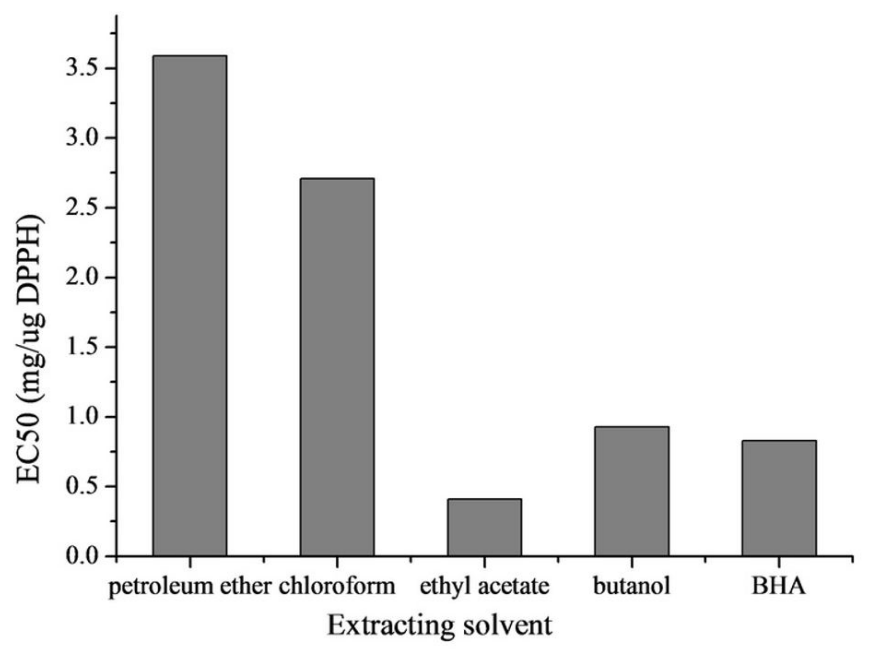

Figure 5. IC50 of lotus rhizome extracts.

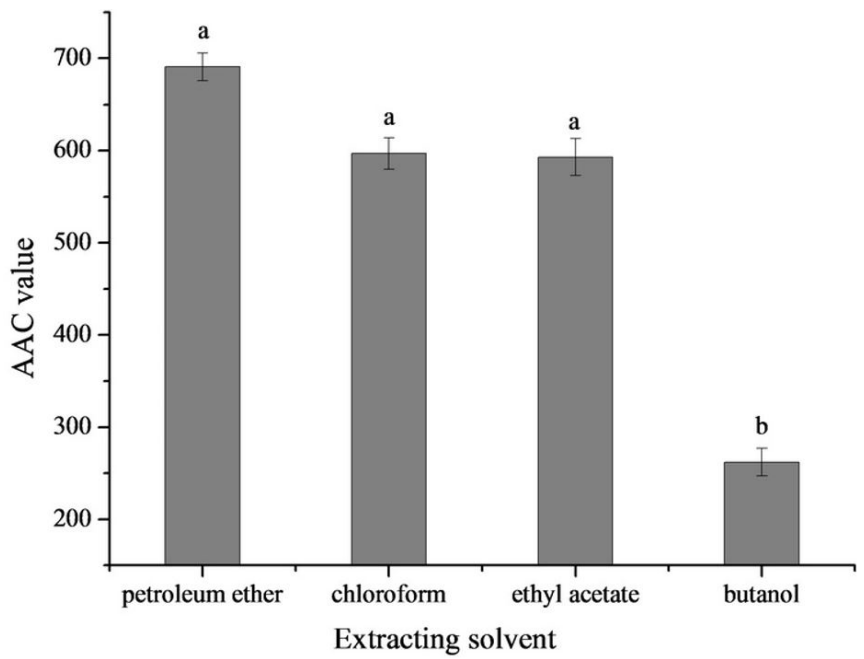

Figure 6. Antioxidant activity of lotus rhizome extracts determined by $\beta$-carotene bleaching method. Values in a column with different letters were significantly different $(P<0.05)$.
There was no significant correlation between the antioxidant activity against $\beta$-carotene-linoleic acid and the total phenolic content $\left(\mathrm{R}^{2}=0.1995\right)$. It could be concluded that not all the antioxidant activities against $\beta$-carotene-linoleic acid were caused by the phenols in lotus rhizome.

\section{Conclusion}

The antioxidant activity of the extract of lotus rhizome with different solvent by gradient extraction was determined in this study. The yield of butanol extract was the highest. The order of total phenolic content in different extracts was as follows: water extract $<$ petroleum ether extract $<$ chloroform extract $<$ butanol extract $<$ ethyl acetate extract, the same with that of the DPPH scavenging activity. The total phenolic content was significantly correlated with DPPH scavenging activity $\left(\mathrm{R}^{2}=0.9363\right)$. All extracts, except water extract with too poor antioxidant activity, showed obvious antioxidant activity against $\beta$-carotene-linoleic acid, and the antioxidant activity of butanol extract was significantly lower than others. There was no significant correlation between the antioxidant activity against $\beta$-carotene-linoleic acid and the total phenolic content $\left(\mathrm{R}^{2}=0.1995\right)$.

\section{References}

Bensky, D., Clavey, S., \& Stoger, E. (2004). Materia medica (pp. 193-194). USA: Eastland Press.

Cho, E. J., Yokozawa, T., Rhyu, D. Y., Kim, S. C., Shibahara, N., \& Park, J. C. (2003). Study on the inhibitory effects of Korean medicinal plants and their main compounds on the 1,1-diphenyl-2picrylhydrazyl radical. Phytomedicine, 10(6-7), 544-551. http:// dx.doi.org/10.1078/094471103322331520. PMid:13678241.

Chopra, R. N., Nayar, S. L., \& Chopra, I. C. (1956). Glossary of Indian medicinal plants. New Delhi: CSIR.

Hu, M., \& Skibsted, L. H. (2002). Antioxidative capacity of rhizome extract and rhizome knot extract of edible lotus (Nelumbo nucifera). Food Chemistry, 76(4), 327-333. http://dx.doi.org/10.1016/S03088146(01)00280-1.

Kartal, N., Sokmen, M., Tepe, B., Daferera, D., Polissiou, M., \& Sokmen, A. (2007). Investigation of the antioxidant properties of Ferula orientalis L. using a suitable extraction procedure. Food Chemistry, 100(2), 584-589. http://dx.doi.org/10.1016/j.foodchem.2005.09.084.

Kashiwada, Y., Aoshima, A., Ikeshiro, Y., Chen, Y.-P., Furukawa, H., Itoigawa, M., Fujioka, T., Mihashi, K., Cosentino, L. M., MorrisNatschke, S. L., \& Lee, K.-H. (2005). Anti-HIV benzylisoquinoline alkaloids and flavonoids from leaves of Nelumbo nucifera, and structureactivity correlations with related alkaloids. Bioorganic \& Medicinal Chemistry Letters, 13(2), 443-448. http://dx.doi.org/10.1016/j. bmc.2004.10.020. PMid:15598565.

Krings, U., \& Berger, R. G. (2001). Antioxidant activity of some roasted foods. Food Chemistry, 72(2), 223-229. http://dx.doi.org/10.1016/ S0308-8146(00)00226-0.

Liu, C. P., Tsai, W. J., Lin, Y. L., Liao, J. F., Chen, C. F., \& Kuo, Y. C. (2004). The extracts from Nelumbo nucifera suppress cell cycle progression, cytokine genes expression, and cell proliferation in human peripheral blood mononuclear cells. Life Sciences, 75(6), 699-716. http://dx.doi. org/10.1016/j.lfs.2004.01.019. PMid:15172179.

Moure, A., Franco, D., Sineiro, J., Dominguez, H., Nunez, M. J., \& Lema, J. M. (2000). Evaluation of extracts from Gevuina avellana hulls as 
antioxidants. Journal of Agricultural and Food Chemistry, 48(9), 3890-3897. http://dx.doi.org/10.1021/jf000048w. PMid:10995287.

Mukherjee, P. K., Saha, K., Das, J., Pal, M., \& Saha, B. P. (1997). Studies on the anti-inflammatory activity of rhizomes of Nelumbo nucifera. Planta Medica, 63(4), 367-369. http://dx.doi.org/10.1055/s-2006-957705. PMid:9270384.

Ono, Y., Hattori, E., Fukaya, Y., Imai, S., \& Ohizumi, Y. (2006). Antiobesity effect of Nelumbo nucifera leaves extract in mice and rats. Journal of Ethnopharmacology, 106(2), 238-244. http://dx.doi. org/10.1016/j.jep.2005.12.036. PMid:16495025.

Sánchez-Moreno, C., Larrauri, J. A., \& Saura-Calixto, F. (1998). A procedure to measure the antiradical efficiency of polyphenols. Journal of Food Agriculture and Environment, 76(2), 270-276. http://dx.doi.org/10.1002/(SICI)1097-0010(199802)76:2<270::AIDJSFA945>3.0.CO;2-9.
Sinha, S., Mukherjee, P. K., Mukherjee, K., Pal, M., Mandal, S. C., \& Saha, B. P. (2000). Evaluation of antipyretic potential of Nelumbo nucifera stalk extract. Phytotherapy Research, 14(4), 272-274. http://dx.doi. org/10.1002/1099-1573(200006)14:4<272::AID-PTR556>3.0.CO;2-H. PMid:10861971.

Slinkard, K., \& Singleton, V. L. (1997). Total phenol analyses: automation and comparison with manual methods. American Journal of Enology and Viticulture, 28(1), 49-55.

Wangensteen, H., Samuelsen, A. B., \& Malterud, K. E. (2004). Antioxidant activity in extracts from coriander. Food Chemistry, 88(2), 293-297. http://dx.doi.org/10.1016/j.foodchem.2004.01.047.

Wu, M. J., Wang, L., Weng, C. Y., \& Yen, J. H. (2003). Antioxidant activity of methanol extract of the lotus leaf (Nelumbo nucifera Gaertn.). The American Journal of Chinese Medicine, 31(5), 687-698. http:// dx.doi.org/10.1142/S0192415X03001429. PMid:14696672. 